\title{
Psikolojik Sağlamlık için Koruyucu Faktörler Ölçeği Türkçe Formunun Geçerlik ve Güvenirliği
}

\author{
Çiğdem Tanko*1, Füsun Ekşi², Osman Hatun ${ }^{3}$ ve Halil Ekşi ${ }^{4}$
}

$\ddot{O}_{z}$

Bu çalışmanın amacı, Psikolojik Sağlamlık için Koruyucu Faktörler Ölçeği’ni (PSKFÖ) Türkçeye uyarlamak ve psikometrik incelemesini yapmaktır. Arastırmanın katılımcıları 256 bireyden (\% 65'i kadın) oluşmaktadır. Katılımcıların yaş ortalaması $30.78^{\prime}$ dir. Araştırmada öncelikle ölçeğin dilsel eş değerlik çalışmaları yapılmıștır. PSKFÖ'nün yapı geçerliği için Doğrulayıcı Faktör Analizi (DFA) yapılmıștır. DFA sonucunda ölçeğin orijinal formdaki gibi üç boyutlu ve 15 maddeli yapısının doğrulandığı ve Türkçe formun iyi uyum değerlerine sahip olduğu görülmüştür $\left(\chi^{2} / s d=1.99 ; \mathrm{p}<.001 ; \mathrm{CFI}=.98\right.$; NNFI = .97; $\mathrm{SRMR}=.053 ; \mathrm{RMSEA}=.062$ ). Ölçeğin iç tutarlılık güvenirliği için Cronbach alpha katsayısı hesaplanmış ve PSKFÖ'nün iç tutarlık katsayısı toplam puan için .93, bireysel boyut için .76, akran boyutu için .87, aile boyutu için .92 olarak saptanmıştır. Ölçüt bağıntı geçerliği için, PSKFÖ ile Kısa Psikolojik Sağlamlık Ölçeği (KPSÖ) arasındaki ilișkiye bakılmış ve ölçek puanları arasında pozitif yönde ve anlamlı bir ilişkiye rastlanmıştır. Analizler sonucunda PSKFÖ’nün Türk örnekleminde geçerli ve güvenilir bir ölçme aracı olduğunu sonucuna ulașılmıștır.

\author{
Anahtar Sözcükler \\ Psikolojik sağlamlık \\ Koruyucu faktörler \\ Ölçek uyarlama \\ Makale Hakkında \\ Gönderim Tarihi \\ 11 Eylül 2020 \\ Kabul Tarihi \\ 03 Mart 2021 \\ Makale Türü \\ Araștırma Makalesi
}

The Validity and Reliability of the Turkish Version of the Protective Factors for Resilience Scale

\section{Abstract}

The aim of the study was to adapt the Protective Factors for Resilience Scale (PFRS) into Turkish and to examine its psychometric properties. The participants of the study consist of 256 individuals ( $65 \%$ women, mean age is 30.78). At first, linguistic equivalence studies of the scale were carried out. For the construct validity of the PFRS, Confirmatory Factor Analysis (CFA) was performed. CFA showed that the threedimensional and 15-item structure of the original scale was acceptable for the Turkish sample and had acceptable goodness of fit values $(\chi 2 / d f=1.99 ; p<.001 ; \mathrm{CFI}=.98 ; \mathrm{NNFI}=.97$; SRMR $=.053$; RMSEA $=.062)$. Cronbach alpha coefficient was calculated for the reliability analysis. The internal consistency of the scale was found to be .93 for the total score, .76 for the individual dimension, .87 for the peer dimension, and .92 for the family dimension. For criterion-related validity, the relationship between PFRS and the Brief Resilience Scale (BRS) was examined and a positive relationship was found between scale scores. Consequently, the findings of the study showed that PFRS is a valid and reliable measurement tool in Turkish sample.
Keywords

Resilience

Protective factors

Scale adaptation

Article Info

Received

September 11, 2020

Accepted

March 03, 2021

Article Type

Research Paper

Atıf: Tanko, Ç., Ekşi, F., Hatun, O. ve Ekşi, H. (2021). Psikolojik Sağlamlık için Koruyucu Faktörler Ölçeği Türkçe formunun geçerlik ve güvenirliği. Ege Eğitim Dergisi, 22(1), 16-29. doi: 10.12984/egeefd.793597

\footnotetext{
* Sorumlu Yazar / Corresponding Author

1 Marmara Üniversitesi, Eğitim Fakültesi, Türkiye, tankocigdem@gmail.com

[D İstanbul Medeniyet Üniversitesi, Eğitim Bilimleri Fakültesi, Türkiye, eksifusun@gmail.com

[D. Sinop Üniversitesi, Eğitim Fakültesi, Eğitim Bilimleri Bölümü, Türkiye, ohatunmt@gmail.com

4 D. Marmara Üniversitesi, Eğitim Fakültesi, Türkiye, h.eksi70@gmail.com
} 


\section{Extended Abstract \\ Introduction}

Individuals may encounter adverse situations such as war, terror, earthquake, flood, and loss of relatives throughout their lives. The capacity of a person to adapt to the changes experienced after these negative situations with the effect of risks and protective factors is explained by the concept of resilience (Karairmak, 2006). The concept of resilience is defined as endurance to emotional dysfunction and psychopathology after traumatic events that cause distress and stress in life and make the person feel helpless (Foa, Cahill, Boscarino, Hobfoll, Lahad, Nally, \& Solomon, 2005); the end of vulnerability or endurance to psychopathology and emotional dysfunction (Morland, Butler, \& Leskin, 2008); the ability to overcome or cope with problems caused by trauma (Wagnild \& Young, 1993; Windle, 2011); and the ability to maintain the psychological functionality level or the capacity to maintain a healthy functionality (Bonanno, Galea, Bucciarelli, \& Vlahov, 2006; Morland et al., 2008).

Individuals with low psychological resilience may experience distress, dysfunction, and psychopathology when faced with a minor stressor that many people can easily overcome (Morland et al., 2008). Therefore, it is emphasized that risk and protective factors are important in terms of resilience of individuals (Karairmak, 2006; Zakeri, Jowkar, \& Razmjoee, 2010). Risk factors for the resilience are adverse events or situations that affect a person's psychological health and healthy adaptation capacity (Karairmak, 2006; Yazıc1, 2019). Situations such as, low IQ, communication difficulties, chronic illnesses, low self-esteem, neurotic personality trait, divorce, parental conflict, negative mental health of parents, physical, sexual and emotional abuse, alcohol and substance abuse, parental loss, domestic violence, low economic income, war or natural disaster, social violence, etc. are among the risk factors for resilience. Another important variable for resilience are protective factors, which facilitate the individual's constructive response to negative experiences (Karairmak, 2006), reduce the effect of risk factors by preventing the problem before it occurs, and increase the resistance of individuals (Terzi, 2006). Normal or high intelligence, academic achievement, autonomy, social competence, having a sense of humor, good health, problem solving skills, self-efficacy, self-confidence, positive family relationships, supportive parents, realistic expectations for the child, peer support, effective social resources (quality schools, youth centers, etc.) are some examples of protective factors (Gizir, 2007; Karaırmak, 2006; Öz \& Y1lmaz, 2009; Şahin \& Güçlü, 2019).

In summary, it is emphasized that persons with high resilience can effectively cope with the negative consequences of traumatic events such as earthquakes, floods, loss and war, and have high recovery and adaptation capacities. It is stated that protective factors have an important role in increasing the resilience level of individuals (Dias \& Cadime, 2017; Hjemdal, Vogel, Solem, Hagen, \& Stiles, 2011; Steinhardt \& Dolbier, 2008). In the literature, there are many scales related to resilience; however, no measurement tool was found related to protective factors for resilience. Therefore, the main purpose of this study was to adapt the Protective Factors for Psychological Resilience Scale (PFRS) developed by Harms, Pooley and Cohen (2017) into Turkish and to examine its psychometric characteristics. Consequently, it is hoped that the study will make an important contribution to both mental health professionals and the literature.

\section{Method}

The purpose of the study was to adapt PFRS to Turkish and to examine its psychometric properties. The original form of the PFRS is scored in 7-point Likert type (1- Strongly disagree, 7- Strongly agree) and consists of 15 items and three sub-dimensions (personal, family, peer). Descriptive survey design was used in this study. The data of the study were collected from 256 participants, 166 female $(65 \%)$ and 90 male $(35 \%)$ with a mean age of 30.78 $(d f=8.4)$. PFRS and Brief Resilience Scale (BRS) were used as data collection tools in the study. CFA was performed for the construct validity of the scale. For the reliability of the PFRS, Cronbach alpha coefficients were calculated. For the item analysis, corrected item-total score correlations were examined. Pearson moments correlation coefficient between PFRS and BRS was calculated for criterion-related validity.

\section{Findings}

The results of the analysis showed that the items in the Turkish and English forms of the PFRS were understood as similar by participants. For the the construct validity of the scale, CFA revealed that the three-dimensional structure of the scale has good fit values also in the Turkish form $\left(\chi^{2} / d f=1.99, p<.001 ; \mathrm{CFI}=.98 ; \mathrm{NNFI}=.97\right.$; $\mathrm{SRMR}=.053$; RMSEA $=.062)$. The factor loads of the items varied .35 and .87 . Corrected item-total score correlations of the PFRS ranged between .33 and .84. The Cronbach alpha coefficient of the scale was found as .93 for the total score. Additionally, a significant and positive correlation between PFRS and BRS was found. As a result of the analysis, it was found that the Turkish version of PFRS, which consists of 15 items and three subdimensions, has a valid and reliable structure. 


\section{Discussion and Conclusion}

Individuals may face adverse or traumatic situations such as war, earthquake, flood, fire, or loss throughout their lives. However, no one is affected by these negative and destructive events at the same level and thanks to the protective factors individuals may have, they can cope with these difficult situations (Kararmak, 2006; Terzi, 2006). In this study, it was aimed to adapt the PFRS developed by Harms et al. (2017) into Turkish and examine its psychometric properties.

As a result of the CFA performed for the construct validity of the scale, CFA revealed that the three-dimensional structure of the scale has good fit values also in the Turkish form (Kline, 2015; Marsh, Hau, Artelt, Baumert, \& Peschar, 2006). For the criterion-related validity, a significant and positive correlation was found between PFRS and BRS. These results are supported in the literature (Dias \& Cadime, 2017; Hjemdal et al., 2011; Steinhardt \& Dolbier, 2008). Therefore, it is safe to conclude that as the PFRS scores increase, the resilience level of the individual will also increase.

For the reliability of PFRS, Cronbach alpha coefficient of the scale was found as .91 for the total score. Reliability values for the sub-dimensions of the scale are .76 and above. Cronbach alpha coefficients of .70 and above are considered sufficient (Tabachnick \& Fidell, 2013). According to these findings, the whole scale and its subdimensions are reliable. In addition, the corrected item-total score correlations of the items in the scale vary between .33 and .84 . Corrected item total correlation values between .30 and .39 are considered good, and 40 and above as very good (Aiken \& Groth Marnat, 2006).

The results of data analysis indicated that the PFRS is a valid and reliable measure. In the literature, no scale related to protective factors for psychological resilience adapted to Turkish was found. The results of this study are expected to make a significant contribution to mental health profession and the literature. 


\section{Giriş}

Psikoloji ilk başlarda insanın zayıf yönleri üzerinde dururken, bu geleneksel anlayışın zor yaşantı ve travma durumlarını çözmede yetersiz kaldığı, insanın değişme ve gelişme gücünü arka plana attığı görülmüştür. Bunun sonucunda insanın doğuştan getirdiği güçlü yanları olduğu ve bu güçlü yanların ortaya konulmasının ve geliştirilmesinin yaşanılan sorunlarla mücadele etme konusunda daha etkili olacağı üzerinde durulmuştur. Bu düşünce yaşanılan olaylar karşısında farklı tepkiler veren ve iyileşme sürelerinin değiştiği insanlar üzerinde araştırmalar yapılmasını sağlamış ve psikolojik sağlamlık (resilience) kavramını gündeme getirmiştir (Apaydın Demirci ve Mersin, 2020; Doğan, 2015; Tümlü, 2012; Ünlü, 2018).

Bireyler yaşamları boyunca yangın, sel, deprem, göç, kayıp, savaş, terör gibi zor ve travmatik durumlarla karşılaşabilirler. Bazı insanlar bu zorlu yaşam olaylarından olumsuz olarak etkilenseler de sonrasında bu durumlara bir şekilde uyum sağlamaktadırlar. Bazıları ise bu travmatik olayların etkisini uzun süre yaşarlar. Bu uyum sağlama sürecini etkileyen en temel faktör bireylerin kendilerini toparlamaları konusunda mücadele etmelerini ve çaba göstermelerini sağlayan psikolojik sağlamlık olgusudur (Basım ve Çetin, 2011). Psikolojik sağlamlık kavramı, Oxford İngilizce-Türkçe Sözlük’te "geri firlama; elastikiyet, esneme; bir felaketten sonra kendini çabuk toparlama” (İz ve Hony, 1978) gibi anlamlara gelmektedir.

Türkçe alanyazında 'resilience' kavramına karşılık olarak kendini toparlama gücü (Terzi, 2006), yılmazlık (Aydoğan ve Eryiğit Madzwamuse, 2019; Gürgan, 2006); dayanıklılık (Basım ve Çetin, 2011; Işık, 2016; Yılmaz, 2019) ve sağlamlık (Arslan, 2015; Aydın ve Egemberdiyeva, 2018; Doğan, 2015; Karaırmak, 2006; Varıcıer, 2019) kavramlarının kullanıldığı görülmektedir. Bu çalışmada ise psikolojik sağlamlık kavramı kullanılacaktır. Psikolojik sağlamlık kavramı, yaşamda sıkıntı ve stres yaratan ve kişiyi çaresiz hissettiren travmatik olaylar sonrasında duygusal işlev bozukluğu ve psikopatolojiye karşı dayanıklılık (Foa, Cahill, Boscarino, Hobfoll, Lahad, Nally ve Solomon, 2005); psikopatoloji ve duygusal işlev bozukluğuna karşı savunmasızlık ya da dayanıksızlık halinin son bulması (Morland, Butler ve Leskin, 2008); travmanın neden olduğu sorunların üstesinden gelme ya da baş etme yeteneği (Wagnild ve Young, 1993; Windle, 2011); psikolojik işlevsellik düzeyini koruma kabiliyeti ya da sağlıklı ve semptom içermeyen bir işlevselliği sürdürmedeki kapasite (Bonanno, Galea, Bucciarelli ve Vlahov, 2006; Morland ve diğ., 2008) olarak tanımlanmaktadır.

Kişiler hayatları boyunca olumsuz durumlarla karşılaşabilirler. Bu olumsuz durumlar karşısında risk faktörleriyle koruyucu faktörlerin etkileşime girmesi sonucu yaşanılan değişikliklere karşı kişinin olumlu bir uyum gösterme durumu psikolojik sağlamlık kavramıyla açıklanmaktadır (Karaırmak, 2006). Psikolojik sağlamlık konusunda yapılan çalışmalara bakıldığgnda stres yaratan durumlar karşısında bireylerin içsel ve dışsal faktörlerden etkilendiği (Zakeri, Jowkar ve Razmjoee, 2010), risk ve koruyucu faktörlerin bireylerin psikolojik sağlamlık düzeyleri açısından önemli olduğu ifade edilmektedir (Karaırmak, 2006).Bu kısımda çalışmanın problemi açık ve net bir biçimde tanımlanır, okuyucuya niçin problem olduğu alanyazından kanıtlarla sunulur. İlgili alanyazın eleştirel bir bakış açısıyla değerlendirilir. Alanyazındaki boşluk vurgulanarak araştırmanın önemi ortaya konur. Giriş kısmı, çalışmanın amacı ve söz konusu amaca ulaşmayı sağlayacak nitelikteki uygun soru/problem cümlesinin ya da hipotezlerin (denence) belirtilmesiyle tamamlanır.

\section{Psikolojik Sağlamlığı Engelleyen Risk Faktörleri}

Bireyin psikolojik sağlığını ve sağlıklı uyum kapasitesini etkileyen olumsuz olay ya da durumlar, psikolojik sağlamlık açısından risk faktörleri olarak değerlendirilmektedir (Karaırmak, 2006; Yazıcı, 2019). Bu risk faktörlerini Öz ve Yılmaz (2019) ve Gizir (2007) bireysel, ailesel ve çevresel; Varıcıer (2019) ve Yazıcı (2019) bireysel, ailesel ve toplumsal; Şahin ve Güçlü (2019) ise kişisel, ailesel ve çevresel olarak sınıflamışlardır. Kişisel risk faktörleri genetik etkiler, düşük IQ, öğrenme güçlüğü, gelişim geriliği, iletişim güçlüğü, kronik rahatsızlıklar, akademik yetersizlikler, düşük öz sayg1, dürtüsellik, düşük sosyal beceri (Aydoğan ve Eryiğit Madzwamuse, 2019); erken doğum, algılanan ebeveyn tutumu, nevrotik kişilik özelliği, duygu odaklı başa çıkma stili, kanser, dış kontrol odağının yüksek olması (Varıcıer, 2019) gibi kavramları içermektedir. Ailesel risk faktörleri parçalanmış aile, değişken ve belirsiz ebeveyn disiplini, ebeveyn çatışması, ebeveynin olumsuz ruh sağlığı, fiziksel, cinsel ve duygusal istismar, ebeveynin suça yatkınlığı, alkol ve madde kullanımı, ebeveyn kaybı, aile içi şiddet (Aydoğan ve Eryiğit Madzwamuse, 2019); otoriter ve izin veren ebeveyn tutumu (Masten, 2001); tek ebeveyn, boşanma, ailede şiddet (Masten ve Powell 2003) gibi kavramları kapsamaktadır. Çevresel risk faktörlerinde ise sosyoekonomik durumun düşüklüğü, serbest zaman etkinliklerine ulaşamama, evsizlik, savaş veya doğal afet, ayrımcılığa maruz kalma, toplumsal şiddet, yaşanılan bölgede riskli davranışların fazlalığı (Aydoğan ve Eryiğit Madzwamuse, 2019) gibi kavramlar yer almaktadır.

\section{Psikolojik Sağlamlık İçin Koruyucu Faktörler}

Psikolojik sağlamlıkta diğer önemli faktör, yaşanan olumsuz deneyimler karşısında bireylerin yapıcı tepki vermesini sağlayan koruyucu faktörlerdir (Karaırmak, 2006). Problemlerin ortaya çıkmadan önce önlenmesi, risk faktörlerinin etkisinin azalması ve bireyin direncinin artmasında koruyucu faktörler etkili olmaktadır (Terzi, 2006). 
Harms, Pooley ve Cohen, (2017) koruyucu faktörleri bireysel, ailesel ve akran olmak üzere üç grupta sınıflamıştır. Gizir'in (2007) derleme çalışmasında ise koruyucu faktörler üç grupta ele alınmıştır:

Bireysel Koruyиси Faktörler. Normalüstü zekâya sahip olma, akademik başarı, olumlu mizaç, özerklik, sosyal açıdan yetkinlik, mizah duygusu (Gizir, 2007); etkili problem çözebilme, öz yeterlik, öz saygı, öz güven, olumlu bakış açısı (Arslan, 2015; Gizir, 2007; Karaırmak, 2006), sosyal becerilere sahip olma, yumuşak başlı ve herkes tarafindan sevilen biri olma (Karaırmak, 2006); güvenli bağlanma deneyimi (Aydoğan ve Eryiğit Madzwamuse, 2019); stresle başa çıkma stilleri (Varıcıer, 2019) gibi kavramları içermektedir.

Zekâ seviyesinin yüksek olması riske karşı koruyucu bir etki oluştururken aynı zamanda bireylerin etkili problem çözme becerilerini geliştirmelerini de sağlamaktadır. Bu da bireylerin sorunlarının üstesinden daha rahat bir şekilde gelmelerini ve karşılaştıkları sorunları daha çabuk bir şekilde aşmalarını sağlamaktadır (Gizir, 2004). Öz güven, öz yeterlik ve benlik saygısı olan kişiler zorluktan kaçmak yerine onun üzerine giderler, başarısız olunan durumlardan bir şeyler öğrenirler. Yaşanılan olumsuz durumlar kendilerini olumsuz algılamalarına sebep olmazken, kendilerine karşı daha affedici ve yapıcı davranırlar. Diğer bir faktör ise iyimserlik ve umuttur. Bireylerin hayata olumlu ve geleceğe umutla bakmaları onların hayata ve yaşadıklarına karşı daha güçlü durmalarını sağlamaktadır (Gizir, 2004).

Ailesel Koruyисu Faktörler. Aile içi olumlu ilişkiler, eğitimli ebeveyne sahip olma, aileyle birlikte yaşama (Öz ve Yılmaz, 2009); destekleyici anne-baba, çocuğa yönelik yüksek ve gerçekçi beklentiler (Gizir, 2007) gibi kavramları içermektedir. Psikolojik sağlamlık, erken çocukluk döneminde ebeveynlerin çocuğa karşı tutumuyla doğru orantılı olarak gelişmeye başlamaktadır (Şahin ve Güçlü, 2019). Baumrind (1971) ebeveyn tutumlarını otoriter, izin verici ve demokratik olarak üçe ayırmıştır. Demokratik ebeveyn tutumunda kontrol, açık iletişim, olgunluk beklentisi ve bakım özellikleri yüksek; otoriter ebeveyn tutumunda açık iletişim ve bakım; izin verici ebeveyn tutumunda ise kontrol ve olgunluk beklentisi düşük olarak görülmektedir. Otoriter ve izin verici ebeveyn tutumlarındaki düşük özellikler psikolojik sağlamlığı olumsuz olarak etkilerken, demokratik ebeveyn tutumunda özelliklerin yüksek çıkması psikolojik sağlamlığı olumlu yönde etkilemektedir (Akt. Yılmaz, 2000).

Çevresel Korиyиси Faktörler. Yakın çevredeki yetişkinlerle olumlu ve destekleyici ilişkilere sahip olma, akranlar tarafından desteklenme, nitelikli okul ve gençlik organizasyonları gibi etkili sosyal çevre kaynaklarına sahip olmak çevresel koruyucu faktörlere örnektir (Gizir, 2007). Okula başlamayla birlikte bireyler toplumsallaşma yolunda ilk adımı atmaya başlarlar. Öncesinde sadece aile önemliyken okulla birlikte bireyin çevresi daha da genişler. Bu çevreye öğretmen, arkadaş grupları ve bireyin katıldığı çeşitli kurs ve etkinliklerdeki diğer bireyler girmekte ve bunlar bireyi etkilemektedir. Bu nedenle ailenin birey üzerindeki etkisi ilk yıllarda çok fazla olsa da sonrasında bu etki çevreye de dağılmakta ve okul, iş yeri, komşuluk ilişkileri gibi farklı ortamlardaki farklı ilişkiler bireyin psikolojik sağlamlık durumunu etkilemektedir.

Özetle koruyucu faktörler içsel ve dışsal kaynaklı olmak üzere iki grupta ele alınabilir. Öz yeterlik, başa çıkma ve aidiyet duygusu psikolojik sağlamlığa katkıda bulunan iç kaynaklar olarak; sosyal destek ve çevresel faktörler ise dış kaynak olarak sınıflandırılabilir (Pooley ve Cohen, 2010).

Psikolojik sağlamlık düzeyi düşük olan bireyler, pek çok insanın kolayca üstesinden gelebileceği küçük bir stresörle karşılaştığında bile büyük bir sıkıntı, işlevsizlik ve hatta psikopatoloji yaşayabilirler (Morland ve diğg., 2008). Psikolojik sağlamlık düzeyi yüksek olan insanların deprem, sel, kayıp ve savaş gibi travmatik olayların olumsuz sonuçları ve zorlu yaşam koşullarıyla etkili bir şekilde baş edebildikleri, toparlanma ve uyum sağlama kapasitelerinin yüksek olduğu vurgulanmaktadır. Dolayısıyla psikolojik açıdan sağlam bireylerin yetiştirilmesi ve zorlu yaşam olayları karşısında insanların psikolojik sağlamlık düzeylerinin arttırılmasında koruyucu faktörlerin rolü yadsınamaz (Dias ve Cadime, 2017; Hjemdal, Vogel, Solem, Hagen ve Stiles, 2011; Martinez Torteya, Anne Bogat, Von Eye ve Levendosky, 2009; Steinhardt ve Dolbier, 2008). Alanyazın incelendiğinde psikolojik sağlamlık ile ilgili birçok ölçek bulunmaktadır (Arslan, 2015; Basım ve Çetin, 2011; Bulut, Doğan ve Altundağ, 2013; Doğan, 2015; Gürgan, 2006; Karaırmak, 2010). Ancak psikolojik sağlamlık için koruyucu faktörleri ortaya koyan bir ölçeğe ulaşılamamıştır. Bu nedenle araştırmada, Harms ve diğerleri (2017) tarafından geliştirilen Psikolojik Sağlamlık İçin Koruyucu Faktörler Ölçeği'nin (PSKFÖ) Türkçeye adaptasyonu ve psikometrik özelliklerinin incelenmesi hedeflenmiştir. Dolaysıyla bu çalışmadan elde edilen bulguların ruh sağlığı çalışanlarına ve alanyazına önemli katkı sunacağı beklenmektedir.

\section{Yöntem}

\section{Araştırmanın Deseni}

Bu araştırmada, Psikolojik Sağlamlık için Koruyucu Faktörler Ölçeği’nin (PSKFÖ) Türkçeye adaptasyonu ve psikometrik özelliklerinin incelenmesi amaçlanmıştır. Yetenek ve tutum testlerinin geliştirilmesi veya uyarlanmasını amaçlayan araştırmaların betimsel araştırma grubuna girdiği ifade edilmektedir (Büyüköztürk, Kılıç Çakmak, Akgün, Karadeniz ve Demirel, 2018). Dolayısıyla bu çalışmanın amacı doğrultusunda araştırmada nicel araştırma türlerinden betimsel tarama deseni kullanılmıştır. 


\section{Çalışma Grubu}

$\mathrm{Bu}$ çalışmanın veri toplama aşaması Covid-19 pandemisi sürecinde gerçekleştiğinden katılımcıların belirlenmesinde uygun örnekleme yöntemi kullanılmıştır. Araştırmanın katılımcılarına İnternet üzerinden elektronik ortamda ulaşılmıştır. Araştırmanın katılımcılarını Marmara Üniversitesi Fen Edebiyat ve Eğitim Fakültelerinde öğrenim gören 150 öğrenci ile devlet okullarında çalışan 106 öğretmen olmak üzere toplam 256 kişi oluşturmaktadır. Öğrencilerin 60'1 rehberlik ve psikolojik danışmanlık, 32'si İngilizce öğretmenliği, 10'u okul öncesi öğretmenliği, 15'i psikoloji, 10'u felsefe, 13'ü tarih ve 10'u coğrafya bölümlerinde öğrenim görmektedir. Öğretmenlerin 49'u sınıf öğretmeni ve 57'si ise psikolojik danışmandır. Yaş ortalaması $30.78(S S=8.4)$ olan katılımcıların 90'1 (\% 35) erkek ve 166's1 (\% 65) kadındır. Katılımcılara ait demografik veriler Tablo 1'de sunulmuştur.

Tablo 1

Katılımciların Demografik Özellikleri

\begin{tabular}{llcc}
\hline Katılımcılar & & $f$ & $\%$ \\
\hline \multirow{2}{*}{ Cinsiyet } & Kadın & 166 & 65 \\
& Erkek & 90 & 35 \\
Ekonomik Düzey & Düşük & 50 & 19.53 \\
& Orta & 160 & 62.5 \\
& Yüksek & 46 & 17.97 \\
Eğitim Fakültesi Öğrencileri & Rehberlik ve Psikolojik Danışmanlık & 60 & 23.44 \\
& İngilizce Öğretmenliği & 32 & 12.5 \\
& Okulöncesi Öğretmenliği & 10 & 3.9 \\
& Psikoloji & 15 & 5.86 \\
Fen Edebiyat Fakültesi Öğrencileri & Felsefe & 10 & 3.9 \\
& Tarih & 13 & 5.1 \\
& Coğrafya & 10 & 3.9 \\
& Sinıf Öğretmeni & 49 & 19.14 \\
& Psikolojik Danışman & 57 & 22.27 \\
\hline
\end{tabular}

\section{Veri Toplama Araçları}

Bu çalışmanın verileri kişisel bilgi formu, Psikolojik Sağlamlık için Koruyucu Faktörler Ölçeği (PSKFÖ) ve Kısa Psikolojik Sağlamlık Ölçeği (KPSÖ) ile toplanmıştır.

Kişisel Bilgi Formu (KBF). Katılımcıların cinsiyeti ve yaşı gibi demografik bilgilerine ilişkin veri toplamak amacıyla araştırmacılar tarafından hazırlanmıştır.

Psikolojik Sağlamlık için Koruyucu Faktörler Ölçeği. Psikolojik Sağlamlık İçin Koruyucu Faktörler Ölçeği (PSKFÖ), psikolojik sağlamlığı etkileyen koruyucu faktörleri belirlemek için geliştirilen bir ölçme aracıdır. Harms ve diğerleri (2017) tarafından geliştirilen ölçek 15 madde ve 3 boyuttan (bireysel, akran ve aile) oluşmaktadır. Ölçekte ters madde bulunmamaktadır. 7'li likert yapıda olan ölçek "Kesinlikle katılmıyorum (7)" ile "Kesinlikle katılıyorum (1)" arasında puanlanmakta ve ölçekten alınan yüksek puan ise yüksek sağlamlık düzeyini belirtmektedir.

Ölçeğin toplam puan için Cronbach alpha iç tutarlılık katsayısı .93 olarak saptanmıştır. Ölçekteki madde faktör yüklerinin .40 ve üstünde olduğu görülmüştür. Doğrulayıcı faktör analizi (DFA) sonucunda ölçeğin uyum indekslerinin $\left(\chi^{2} / s d=2.33, p=.000 ; \mathrm{RMSEA}=.056, \mathrm{CFI}=.99 ; \mathrm{SRMR}=.05 ; \mathrm{GFI}=.89\right)$ iyi düzeyde olduğu belirtilmiştir.

Kısa Psikolojik Săglamlık Ölçeği (KPSÖ). KPSÖ, Smith ve diğerleri (2008) tarafindan bireylerin psikolojik sağlamlığını ölçebilmek amacıyla geliştirilen KPSÖ, 6 maddelik, tek faktörlü bir ölçme aracıdır. Ölçme aracı "Hiç uygun değil (1)" ile "Tamamen uygun (5)" arasında derecelendirilmektedir. Ölçekte 2, 4 ve 6. maddeler tersten kodlanmıştır. Ölçeğin Türkçeye uyarlama çalışması Doğan (2015) tarafından yapıllmıştır. 
Ölçeğin iç tutarlık kat sayısı .83 olarak hesaplamıştır. Ölçeğin düzeltilmiş madde toplam korelasyonları .49 ile .66 arasında değişmektedir. DFA sonucunda, ölçeğin iyi uyum değerlerine $\left(\chi^{2} / s d=1,83, \mathrm{NFI}=.99, \mathrm{NNFI}=.99, \mathrm{CFI}\right.$ $=.99, \mathrm{GFI}=.99, \mathrm{AGFI}=.96, \mathrm{RMSEA}=.05, \mathrm{SRMR}=.03)$ sahip olduğu ve madde faktör yüklerinin .52 ve üstünde olduğu bulunmuştur.

\section{Veri Toplama Süreci}

$\mathrm{Bu}$ araştırmanın verileri Mayıs-Haziran 2020 tarihlerinde İnternet üzerinden Google Formlar uygulaması aracılığıyla toplanmıştır. Veri Toplama Formunun linki, Marmara Üniversitesi Eğitim Fakültesi ve Fen Edebiyat Fakültesi öğretim elemanları aracılığıyla ders amaçlı açılan öğrenci WhatsApp gruplarında ve araştırmanın ilk yazarının dahil olduğu bilgi paylaşım amacıyla açılan öğretmen WhatsApp gruplarında paylaşılmıştır. Katılımcıların bilgilendirilmiș onamları alınmıștır. Bilgilendirilmiş onamda araştırmanın amacı, kișisel bilgilerin gizli kalacağı ve verilerin yalnızca araştırma için kullanılacağı, katılımcıların istediği anda çalışmayı sonlandırabilecekleri ve çalışmaya katılım için gönüllülük şartı gibi bilgilere yer verilmiştir. Katılımcıların veri toplama araçlarını yaklaşık olarak 15 dakikada yanıtladıkları görülmüştür.

\section{Veri Analizi}

PSKFÖ'nün adaptasyon çalışmasında ölçeğin dilsel eş değerliği için eşleştirilmiş gruplar $t$ testi yapılmıştır. Uyarlama çalışmalarında daha önceden belirlenen yapı test edildiği için DFA önerilir (Çokluk, Şekercioğlu ve Büyüköztürk, 2012). Bu nedenle PSKFÖ'nün yapı geçerliği için DFA tercih edilmiştir. Ölçüt bağıntı geçerliği açısından PSKFÖ ile KPSÖ arasındaki ilişkiler için Pearson moment korelasyon katsayısına bakılmıştır.

PSKFÖ'nün güvenirliği için Cronbach alpha iç tutarlık katsayıları incelenmiştir. Ölçekteki maddelerin ayırt edicilik gücünün belirlenmesinde ise düzeltilmiş madde-toplam puan korelasyonu hesaplanmıştır. Çalışmada verilerin analizi için SPSS ve LISREL programlarından yararlanılmıştır.

\section{Etik Konular}

Araştırmada öncelikle PSKFÖ'yü geliştiren yazarlardan ölçek uyarlama izni alınmıştır. Tüm katılımcılardan elektronik ortamda bilgilendirilmiş onamları alınmış, gönüllü katılımcılardan araştırma verileri toplanmıştır.

\section{Dilsel Eș Değerliğe İlișkin Bulgular}

\section{Bulgular}

Ölçek maddeleri 5 uzman tarafindan Türkçeye çevrilmiş ve bu maddeler anlaşılırlık ve dil bilgisi açısından 4 alan uzmanınca kontrol edilerek ölçeğin Türkçe formu hazırlanmıştır. Daha sonra ölçek maddeleri Türkçeden İngilizceye geri çevrilmiş ve son değerlendirmelerden sonra Türkçe forma son şekli verilerek uygulamaya geçilmiştir.

Ölçek, İngilizce öğretmenliği son sınıf öğrencilerine 2 hafta arayla (önce İngilizce sonra ise Türkçe form) uygulanmıştır. Ölçeğin dilsel eş değerliğine ilişkin analiz sonuçları Tablo 2'de verilmiştir.

Tablo 2

PSKFÖ'nün Dilsel Eş Değerliği için Yapılan Eşleştirilmiş Gruplar t Testi Sonuçları

\begin{tabular}{|c|c|c|c|c|c|c|c|}
\hline \multirow{2}{*}{ Maddeler } & \multirow{2}{*}{$N$} & \multirow{2}{*}{$\bar{X}$} & \multirow{2}{*}{$S S$} & \multirow{2}{*}{$\mathrm{Sh}_{\overline{\mathrm{x}}}$} & \multicolumn{3}{|c|}{$t$ testi } \\
\hline & & & & & $t$ & $s d$ & $p$ \\
\hline İngilizce 1 & 32 & 5.69 & 1.28 & 0.23 & \multirow{2}{*}{1.40} & \multirow{2}{*}{31} & \multirow{2}{*}{.17} \\
\hline Türkçe 1 & 32 & 5.22 & 1.50 & 0.26 & & & \\
\hline İngilizce 2 & 32 & 5.41 & 1.39 & 0.25 & \multirow{2}{*}{-.587} & \multirow{2}{*}{31} & \multirow{2}{*}{.561} \\
\hline Türkçe 2 & 32 & 5.56 & 1.01 & 0.18 & & & \\
\hline İngilizce 3 & 32 & 5.06 & 1.87 & 0.33 & \multirow{2}{*}{-1.52} & \multirow{2}{*}{31} & \multirow{2}{*}{.14} \\
\hline Türkçe 3 & 32 & 5.56 & 1.41 & 0.25 & & & \\
\hline İngilizce 4 & 32 & 5.47 & 1.67 & 0.29 & \multirow{2}{*}{0.00} & \multirow{2}{*}{31} & \multirow{2}{*}{1.00} \\
\hline Türkçe 4 & 32 & 5.47 & 1.63 & 0.29 & & & \\
\hline İngilizce 5 & 32 & 5.97 & 1.31 & 0.23 & \multirow{2}{*}{0.00} & \multirow{2}{*}{31} & \multirow{2}{*}{1.00} \\
\hline Türkçe 5 & 32 & 5.97 & 1.31 & 0.23 & & & \\
\hline İngilizce 6 & 32 & 5.44 & 1.50 & 0.27 & \multirow{2}{*}{-.26} & \multirow{2}{*}{31} & \multirow{2}{*}{.79} \\
\hline Türkçe 6 & 32 & 5.50 & 1.37 & 0.24 & & & \\
\hline
\end{tabular}


Tablo 2 - Devam

PSKFÖ'nün Dilsel Eş Değerliği için Yapılan Eşleştirilmiş Gruplar t Testi Sonuçları

\begin{tabular}{|c|c|c|c|c|c|c|c|}
\hline \multirow{2}{*}{ Maddeler } & \multirow{2}{*}{$N$} & \multirow{2}{*}{$\bar{X}$} & \multirow{2}{*}{$S S$} & \multirow{2}{*}{$\mathrm{Sh}_{\overline{\mathrm{x}}}$} & \multicolumn{3}{|c|}{$t$ testi } \\
\hline & & & & & $t$ & $s d$ & $p$ \\
\hline İngilizce 7 & 32 & 5.44 & 1.34 & 0.24 & \multirow{2}{*}{-.22} & \multirow{2}{*}{31} & \multirow{2}{*}{.83} \\
\hline Türkçe 7 & 32 & 5.50 & 1.34 & 0.24 & & & \\
\hline İngilizce 8 & 32 & 5.53 & 1.50 & 0.27 & \multirow{2}{*}{1.13} & \multirow{2}{*}{31} & \multirow{2}{*}{27} \\
\hline Türkçe 8 & 32 & 5.94 & 1.56 & 0.28 & & & \\
\hline İngilizce 9 & 32 & 5.41 & 1.48 & 0.26 & \multirow{2}{*}{-1.15} & \multirow{2}{*}{31} & \multirow{2}{*}{.26} \\
\hline Türkçe 9 & 32 & 5.56 & 1.58 & 0.28 & & & \\
\hline İngilizce 10 & 32 & 5.94 & 1.63 & 0.29 & \multirow{2}{*}{.26} & \multirow{2}{*}{31} & \multirow{2}{*}{.79} \\
\hline Türkçe 10 & 32 & 5.84 & 1.53 & 0.27 & & & \\
\hline İngilizce 11 & 32 & 5.50 & 1.52 & 0.27 & \multirow{2}{*}{.102} & \multirow{2}{*}{31} & \multirow{2}{*}{.92} \\
\hline Türkçe 11 & 32 & 5.47 & 1.65 & 0.29 & & & \\
\hline İngilizce 12 & 32 & 5.69 & 1.40 & 0.25 & \multirow{2}{*}{.57} & \multirow{2}{*}{31} & \multirow{2}{*}{.58} \\
\hline Türkçe 12 & 32 & 5.50 & 1.59 & 0.28 & & & \\
\hline İngilizce 13 & 32 & 5.44 & 1.56 & 0.28 & \multirow{2}{*}{1.29} & \multirow{2}{*}{31} & \multirow{2}{*}{21} \\
\hline Türkçe 13 & 32 & 5.03 & 1.80 & 0.32 & & & \\
\hline İngilizce 14 & 32 & 5.84 & 1.17 & 0.21 & \multirow{2}{*}{.65} & \multirow{2}{*}{31} & \multirow{2}{*}{.52} \\
\hline Türkçe 14 & 32 & 5.69 & 1.47 & 0.26 & & & \\
\hline İngilizce 15 & 32 & 6.28 & 1.22 & 0.22 & \multirow{2}{*}{.49} & \multirow{2}{*}{31} & \multirow{2}{*}{63} \\
\hline Türkçe 15 & 32 & 6.16 & 1.25 & 0.22 & & & \\
\hline
\end{tabular}

Tablo 2'de görülebileceği üzere, ölçeğin İngilizce ve Türkçe formlarındaki maddelerin aritmetik ortalamalarına ilişkin eşleştirilmiş gruplar t testi sonucunda anlamlı bir fark görülmemiştir $(p>.05)$. Bu bulgulardan hareketle ölçeğin dilsel eş değerlik ölçütlerini karşıladığı söylenebilir.

\section{Yapı Geçerliği}

PSKFÖ’nün orijinal formu bireysel, akran ve aile olmak üzere üç faktörden oluşmaktadır. DFA sonucunda elde edilen uyum indeksleri $\left(\chi_{(87, N=256)}^{2}=179.80, p<.001\right.$; CFI $=.98 ; \mathrm{NNFI}=.97$; SRMR $\left.=.053 ; \mathrm{RMSEA}=.062\right)$ incelendiğinde ölçeğin üç boyutlu yapısının Türkçe formda da iyi uyum (Kline, 2015) verdiği görülmüştür.

Ölçekteki maddelerin yol katsayılarına ilişkin faktör yükleri .35 ile .87 arasındadır. PSKFÖ’nün üç boyutlu faktör yapısı ve DFA sonucunda ulaşılan standardize değerler Şekil 1'de sunulmuştur. 


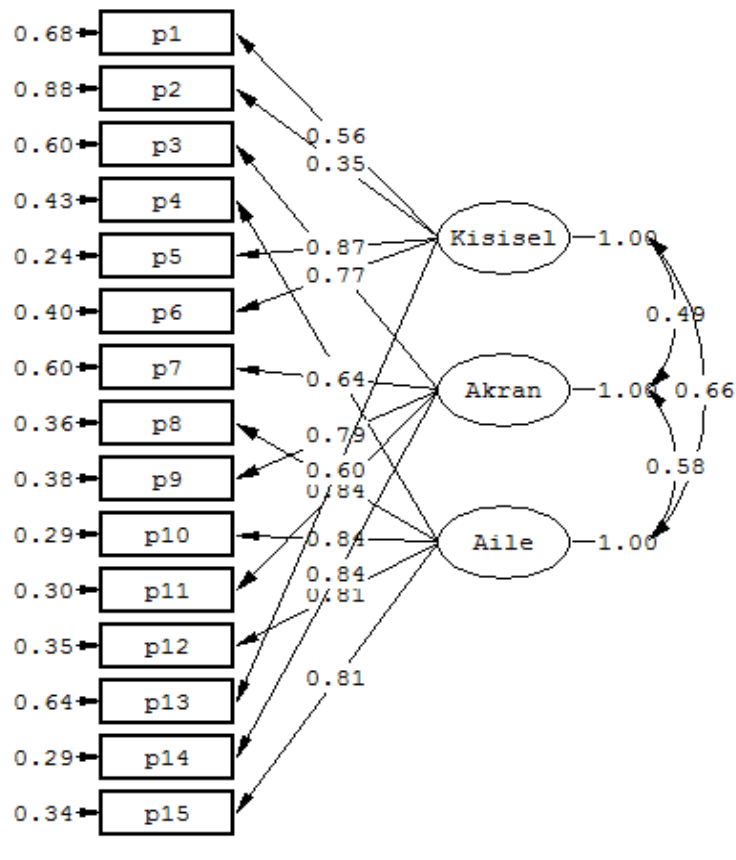

Chi-Square=173.24, df=87, P-value=0.00000, RMSEA $=0.062$

Şekil 1. PSKFÖ'nün yol diyagramı ve faktör yükleri

\section{Ölçüt Bağıntı Geçerliği}

PSKFÖ'nün ölçüt-bağıntılı geçerliği için KPSÖ ile arasındaki ilişkiye bakılmış ve sonuçlar Tablo 3 'te sunulmuştur.

Tablo 3

PSKFÖ ve KPSÖ Arasındaki İlişkilere Yönelik Korelasyon Katsaylları

\begin{tabular}{lcc}
\hline Ölçekler & 1 & 2 \\
\hline 1. PSKFÖ & 1 & 1 \\
2. KPSÖ & $.282^{* *}$ & 18.66 \\
Ortalama & 84.14 & 4.13 \\
Standart Sapma & 12,06 & \\
\hline
\end{tabular}

$* * p<0.01$

Tablo 3’te görüldüğü gibi PSKFÖ ile KPSÖ puanları arasında anlamlı ve pozitif yönlü korelasyon $(r=.282, p<$ $.01)$ bulunmuştur.

\section{Madde Analizi ve Güvenirlik}

Ölçekteki maddelerin toplam puanı yordayıcı gücü ve ayırt ediciliğini saptamak amacıyla yapılan analize ilişkin sonuçlar Tablo 4’te sunulmuştur.

Tablo 4

PSKFÖ’nün Düzeltilmiş Madde Toplam Test Korelasyonlarl ve Betimsel Ístatistikler

\begin{tabular}{lcccccc}
\hline Madde No & Min & Max & $\bar{X}$ & $S S$ & $r_{m d a}$ & $r_{m d t}$ \\
\hline M1 & 1 & 7 & 4.97 & 1.66 & .47 & .50 \\
M2 & 1 & 7 & 4.79 & 1.99 & .26 & .33 \\
M5 & 1 & 7 & 5.88 & 1.48 & .72 & .70 \\
M6 & 1 & 7 & 5.43 & 1.50 & .64 & .71 \\
M13 & 1 & 7 & 4.99 & 1.68 & .56 & .50 \\
\hline
\end{tabular}


Tablo 4 - Devam

PSKFÖ’nün Düzeltilmiş Madde Toplam Test Korelasyonlarl ve Betimsel Ístatistikler

\begin{tabular}{lcccccc}
\hline Madde No & Min & Max & $\bar{X}$ & $S S$ & $r_{m d a}$ & $r_{m d t}$ \\
\hline M3 & 1 & 7 & 5.28 & 1.75 & .56 & .60 \\
M7 & 1 & 7 & 4.93 & 1.63 & .50 & .60 \\
M9 & 1 & 7 & 5.56 & 1.41 & .73 & .74 \\
M11 & 1 & 7 & 5.31 & 1.62 & .61 & .75 \\
M14 & 1 & 7 & 5.33 & 1.56 & .65 & .77 \\
M4 & 1 & 7 & 5.99 & 1.64 & .70 & .74 \\
M8 & 1 & 7 & 5.98 & 1.50 & .73 & .84 \\
M10 & 1 & 7 & 6.15 & 1.49 & .76 & .84 \\
M12 & 1 & 7 & 5.97 & 1.55 & .71 & .81 \\
M15 & 1 & 7 & 6.23 & 1.34 & .74 & .78 \\
\hline
\end{tabular}

$\mathbf{r}_{\mathbf{m d t}}=$ Ölçeğin tamamı madde toplam puan korelasyonu, $\mathbf{r}_{\mathbf{m d a}}=$ Alt boyutlar için madde toplam puan korelasyonu

Tablo 4'te görüldüğü üzere ölçekteki maddelerin düzeltilmiş madde toplam puan korelasyonları .33 ile .84, arasında değişmektedir. Ölçeğin Cronbach alpha iç tutarlılık katsayısı toplam puan için .91, bireysel boyut için .76 , akran boyutu için .87 ve aile boyutu için .92 'dir.

\section{Sonuç ve Tartışma}

Yaşam boyunca insanlar savaş, deprem, sel, yangın, kayıp gibi pek çok olumsuz durumla karşılaşabilirler. Ancak herkes bu olumsuz ve yıpratıcı olaylardan aynı düzeyde etkilenmemekte ve sahip olduğu koruyucu faktörler sayesinde bu güç durumların üstesinden gelebilmektedirler (Karaırmak, 2006; Terzi, 2006). Dolayısıyla bu çalışmada PSKFÖ’nün (Harms ve diğ., 2017) Türkçeye uyarlanması ve geçerlik-güvenirlik analizlerinin yapılması amaçlanmıştır. Araştırmada öncelikle dilsel eş değerlik çalışması yürütülmüş, ölçeğin İngilizce ve Türkçe formlarındaki maddelerin anlam açısından birbirlerine yakın olduğu anlaşılmıştır. Dilsel eş değerlik çalışmasından sonra ölçeğin yapı geçerliği için DFA yapılmış, güvenirliği için Cronbach Alpha katsayısı hesaplanmış ve ölçüt bağıntılı geçerliği için ise KPSÖ ile arasındaki korelasyonlar hesaplanmıştır.

PSKFÖ’nün orijinal formundaki üç faktörlü yapının mevcut çalışmada da tekrar edip etmediğini belirlemek üzere yapılan DFA sonucunda ölçeğin uyum indekslerinin kabul edilebilir uyum değerlerine sahip olduğu (Kline, 2015; Marsh, Hau, Artelt, Baumert ve Peschar, 2006) ve ölçeğin üç boyutlu yapısının bu araştırmada da geçerli olduğu sonucuna ulaşılmıştır. Ölçekteki maddelerin ayırt ediciliğini belirlemek amacıyla yapılan madde analizi sonucunda düzeltilmiş madde toplam puan korelasyonlarının .33 ile .84 arasında değiştiği saptanmıştır. Düzeltilmiş madde toplam korelasyon değerlerinin .30 ile .39 arasında olması iyi, .40 ve üstünde olması ise çok iyi olarak kabul edilmektedir (Aiken ve Groth Marnat, 2006). Bu verilerden hareketle PSKFÖ’nün madde ayırt edicilik gücünün iyi düzeyde olduğu söylenebilir.

PSKFÖ’nün ölçüt-bağıntılı geçerliği için KPSÖ (Doğan, 2015) ile arasındaki ilişkiye bakılmış ve ölçek puanları arasında pozitif ve anlamlı bir ilişki saptanmış, ancak bu ilişkinin düşük düzeyde olduğu görülmüştür. Türkçe alanyazında psikolojik sağlamlık için koruyucu faktörleri ölçen bir ölçme aracına rastlanmadığından bu çalışmada ölçüt bağıntı geçerliği için KPSÖ kullanılmıştır. KPSÖ bireylerin psikolojik sağlamlık düzeylerini değerlendirirken; PSKFÖ ise bireylerin psikolojik sağlamlıklarını arttıran koruyucu faktörlere ne düzeyde sahip olduklarını değerlendirmektedir. Dolayısıyla her iki ölçme aracının da aynı olguyu ölçmemesi nedeniyle aralarındaki korelasyon değeri düşük çıkmış olabilir. Ancak KPSÖ ile PSKFÖ arasındaki korelasyon değeri düşük çıkmış olsa da psikolojik sağlamlık için koruyucu faktörler puanları arttıkça bireyin psikolojik sağlamlık düzeyinin de artacağı söylenebilir. Alanyazın incelendiğinde de bu sonuçlarla örtüşen bulgular görülmektedir. Martinez Torteya ve diğerlerinin (2009) 190 çocuk ve anneleriyle yaptığı çalışmada aile içi şiddete maruz kalan çocukların psikolojik sağlamlık düzeyleri açısından risk ve koruyucu faktörlerin rolü incelenmiş ve sonuçta psikolojik sağlamlık düzeyi yüksek olan kişilerin daha fazla koruyucu faktörlere ve daha az risk faktörlerine sahip oldukları bulunmuştur. Steinhardt ve Dolbier'in (2008) üniversite öğrencileri örnekleminde gerçekleştirdiği deneysel çalışmada psikolojik sağlamlık düzeyleri yüksek olan kişilerin etkili başa çıkma stratejileri ve koruyucu faktörler (olumlu duygulanım, benlik saygısı ve öz liderlik) açısından yüksek puanlara sahip oldukları bulunmuştur. Dias ve Cadime (2017) psikolojik sağlamlığın hedef belirleme ve dürtü kontrolünün yanı sıra okul, ev, topluluk ve akran ortamı gibi koruyucu faktörlerle pozitif korelasyon gösterdiğini bulmuştur. Başka bir çalışmada ise yüksek 
psikolojik sağlamlık puanlarının daha düşük depresyon, anksiyete, stres ve obsesif-kompulsif belirtiler gibi risk faktörleri puanları yordadığı bulunmuştur (Hjemdal ve diğ., 2011).

PSKFÖ’nün toplam puan için Cronbach alpha iç tutarlılık katsayısı .91 olarak hesaplanmıştır. Ölçeğin alt boyutlarına bakıldığında ise iç tutarlık katsayıları.76 ile .92 arasında değişmektedir. Harms ve diğerlerinin (2017) çalışmasında ise PSKFÖ'nün iç tutarlılık katsayısı toplam puan için .93 olarak hesaplanmış, alt boyutlarda ise iç tutarlık katsayısı .70 ile .86 arasında değişmektedir. Güvenirlik açısından ölçeğin Cronbach alpha değerlerinin .70 ve üstünde olması yeterli görülmektedir (Tabachnick ve Fidell, 2013). Bu bulgulardan hareketle ölçeğin güvenirlik ölçütlerini karşıladığı söylenebilir.

Bu çalışmanın sınırlılıkları bulunmaktadır. Ölçek öz bildirim yoluyla cevaplandığı için sosyal beğenirlik, merkezi yığılma gibi dezavantajları bulunmaktadır (Caputo, 2017; Dağ, 2005; Tavşancıl, 2010). Diğer yandan ölçeğin yanıtlanmasının kısa zaman alması ve pratik olması araştırmacılara kolaylık sunmaktadır. Bu çalışma Fen Edebiyat Fakültesi ile Eğitim Fakültesinde öğrenim gören öğrencilerle ve devlet okullarında çalışan öğretmenlerle yapılmıştır. Sonraki çalışmalarda ise farklı bölümlerde öğrenim gören öğrenciler ve özel sektör çalışanları da araştırma sürecine dahil edilebilir. Çalışma 18 yaş ve üstündeki bireylerle gerçekleştirilmiştir. Araştırmanın katılımcıları, psikolojik rahatsızlıklar ve travma öyküsüne sahip olma açısından ele alınmamıştır. Sonraki çalışmalarda ise klinik örneklemin de dahil edildiği karşılaştırmalı araştırmaların yapılması önerilmektedir.

Araştırma sonucunda elde edilen bulgular incelendiğinde, riskli ve stresli durumlar karşısında bireyin psikolojik sağlamlığını koruyan faktörleri belirlemeyi amaçlayan PSKFÖ Türkçe formunun geçerli ve güvenilir bir ölçme aracı olduğu görülmüştür. Alanyazında Türkçeye uyarlanmış koruyucu faktörler ile ilgili ölçeklerin bulunmadığı düşünüldüğünde bu çalışmanın ruh sağlığı çalışanlarına ve alanyazına önemli katkı sağlayacağı düşünülmektedir.

Etik Kurul İzin Bilgisi: Bu araştırma, Marmara Üniversitesi Ĕ̆itim Bilimleri Enstitüsü Araştırma ve Yayın Etiği Kurulunun 25/08/2020 tarihli 2000223293 sayılı kararı ile alınan izinle yürütülmüştür. 


\section{Kaynakça / References}

Aiken, L., \& Groth Marnat, G. (2006). Psychological testing and assessment. Boston: Allyn and Bacon.

Apaydın Demirci, Z. ve Mersin, S. (2020). Pozitif psikolojinin krizle baş etmede önemi. Humanities Sciences (NWSAHS), 15(1), 36-44. doi: 10.12739/NWSA.2020.15.1.4C0233

Arslan, G. (2015). Ergenlerde psikolojik sağlamlık: Bireysel koruyucu faktörlerin rolü. Türk Psikolojik Danışma ve Rehberlik Dergisi, 5(44), 73-82.

Aydın, M. ve Egemberdiyeva, A. (2018). Üniversite öğrencilerinin psikolojik sağlamlık düzeylerinin incelenmesi. Türkiye Ĕ̈itim Dergisi, 3(1), 37-53.

Aydoğan, D. ve Eryiğit Madzwamuse, S. (2019). Okullarda yllmazlığı güçlendirme el kitabı tüm okul yaklaşımı. Ankara: Pegem Akademi.

Basım, H. N. ve Çetin, F. (2011). Yetişkinler için Psikolojik Dayanıklılık Ölçeği’nin güvenirlilik ve geçerlilik çalışması. Türk Psikiyatri Dergisi, 22(2), 104-116.

Bonanno, G. A., Galea, S., Bucciarelli, A., \& Vlahov, D. (2006). Psychological resilience after disaster: New York City in the after math of the September 11th terrorist attack. Psychological Science, 17(3), 181-186. doi: $10.1111 / j .1467-9280.2006 .01682 . x$

Bulut, S., Doğan, U. ve Altundağ, Y. (2013). Adolescent Psychological Resilience Scale: Validity and reliability study. Suvremena Psihologija, 16(1), 21-32

Büyüköztürk, Ş., Kılıç Çakmak, E., Akgün, Ö. E., Karadeniz, Ş. ve Demirel, F. (2018). Bilimsel araştırma yöntemleri (24. baskı). Ankara: Pegem Akademi Yayınevi.

Caputo, A. (2017). Social desirability bias in self-reported well-being measures: Evidence from an online survey. Universitas Psychologica, 16(2), 245-255.

Çokluk, Ö., Şekercioğlu, G. ve Büyüköztürk, Ş. (2012). Sosyal bilimler için çok değişsenli istatistik: SPSS ve LISREL uygulamaları (2. baskı). Ankara: Pegem Akademi.

Dăg, İ. (2005). Psikolojik test ve ölçeklerde geçerlik ve güvenirlik. Psikiyatri Psikoloji Psikofarmakoloji Dergisi, $13(4), 17-23$.

Dias, P. C., \& Cadime, I. (2017). Protective factors and resilience in adolescents: The mediating role of selfregulation. Psicología Educativa, 23(1), 37-43. doi: 10.1016/j.pse.2016.09.003

Doğan, T. (2015). Kısa Psikolojik Sağlamlık Ölçeğinin Türkçe'ye uyarlanması: Geçerlilik ve güvenirlilik çalışması. The Journal of Happiness \& Well-Being, 3(1), 93-102.

Foa, E. B., Cahill, S. P., Boscarino, J. A., Hobfoll, S. E., Lahad, M., Mc Nally, R. J., \& Solomon, Z. (2005). Social, psychological, and psychiatric interventions following terrorist attacks: Recommendations for practice and research. Neuro Psychopharmacology, 30(10), 1806-1817.

Gizir, C. A. (2004). Academic resilience: An investigation of protective factors contributing to the academic achievement of eight grade students in poverty. (Unpublished doctoral dissertation). Orta Doğu Teknik Üniversitesi, Ankara.

Gizir, C. A. (2007). Psikolojik sağlamlık, risk faktörleri ve koruyucu faktörler üzerinde bir derleme çalışması. Türk Psikolojik Danışma ve Rehberlik Dergisi, 3(28),113-128.

Gürgan, U. (2006). Yılmazlık Ölçeği (YÖ): Ölçek geliştirme, güvenirlik ve geçerlik çalışması. Ankara Üniversitesi Eğitim Bilimleri Fakültesi Dergisi, 39(2), 45-74.

Harms, C., Pooley, J. A., \& Cohen, L. (2017). The protective factors for resilience scale (PFRS): Development of the scale. Cogent Psychology,4(1), 1-16. doi: 10.1080/23311908.2017.1400415

Hjemdal, O., Vogel, P. A., Solem, S., Hagen, K., \& Stiles, T. C. (2011). The relationship between resilience and levels of anxiety, depression, and obsessive - compulsive symptoms in adolescents. Clinical Psychology \& Psychotherapy, 18(4), 314-321. doi: 10.1002/cpp.719 
Işık, Ş. (2016). Psikolojik dayanıklılık ölçeğinin geliştirilmesi: Geçerlilik ve güvenirlilik çalışması. The Journal of Happiness \& Well-Being, 4(2), 165-182.

Karaırmak, Ö. (2006). Psikolojik sağlamlık, risk faktörleri ve koruyucu faktörler. Türk Psikolojik Danışma ve Rehberlik Dergisi, 3(26), 129-142.

Kararrmak, Ö. (2010). Establishing the psychometric qualities of the Connor-Davidson Resilience Scale (CDRISC) using exploratory and confirmatory factor analysis in a trauma survivor sample. Psychiatry Research, 179(3), 350-356. doi: 10.1016/j.psychres.2009.09.012

Kline, R. B. (2015). Principles and practice of structural equation modeling (4th ed.). New York: Guilford Publications.

Marsh, H. W., Hau, K. T., Artelt, C., Baumert, J., \& Peschar, J. L. (2006). OECD's brief self-report measure of educational psychology's most useful affective constructs: Cross-cultural, psychometric comparisons across 25 countries. International Journal of Testing, 6(4), 311-360. doi: 10.1207/s15327574ijt0604_1

Martinez Torteya, C., Anne Bogat, G., Von Eye, A., \& Levendosky, A. A. (2009). Resilience among children exposed to domestic violence: The role of risk and protective factors. Child Development, 80(2), 562-577. doi: $10.1111 / j .1467-8624.2009 .01279 . x$

Masten, A. S. (2001). Ordinary magic: Resilience processes in development. American Psychologist, 56, 227-238. doi: $10.1037 / / 0003-066$ X.56.3.227

Masten, A. S., \& Powell, J. L. (2003). A resilience framework for research, policy, and practice. In S. Luthar (Ed.), Resilience and vulnerabilities: Adaptation in the context of childhood adversities (pp. 1-25). New York: Cambridge University Press.

Morland, L. A., Butler, L. D., \& Leskin, G. A. (2008). Resilience and thriving in a time of terrorism. In S. Joseph \& P. A. Linley (Eds.), Trauma, recovery, and growth: Positive psychological perspectives on posttraumatic stress (pp. 39-61). New Jersey: John Wiley \& Sons, Inc.

Öz, F. ve Yılmaz, E. B.(2009). Ruh sağlığının korunmasında önemli bir kavram: Psikolojik sağlamlık. Hacettepe Üniversitesi Hemşirelik Fakültesi Dergisi, 16(3), 82-89.

Pooley, J. A., \& Cohen, L. (2010). Resilience: A definition in context. Australian Community Psychologist, 22, 30-37.

Steinhardt, M., \& Dolbier, C. (2008). Evaluation of a resilience intervention to enhance coping strategies and protective factors and decrease symptomatology. Journal of American College Health, 56(4), 445-453. doi: 10.3200/JACH.56.44.445-454

Şahin, T. ve Güçlü, M. (2019). Sporda psikolojik dayanıklllık. Ankara: Pegem Akademi.

Tabachnick, B. G., \& Fidell, L. S. (2013). Using multivariate statistics (6th ed.). Boston, MA: Pearson Education.

Tavşancıl, E. (2010). Tutumların ölçülmesi ve SPSS ile veri analizi (4. baskı). Ankara: Nobel Yayıncılık.

Terzi, Ş. (2006). Kendini toparlama gücü ölçeğinin uyarlanması: Geçerlik ve güvenirlik çalışmaları. Türk Psikolojik Danışmanlık ve Rehberlik Dergisi, 26, 77-86.

Tümlü, G. Ü. (2012). Psikolojik dayanıklllık düzeyleri farklı üniversite öğrencilerinin temas engellerinin incelenmesi. (Yayımlanmamış yüksek lisans tezi). Hacettepe Üniversitesi, Ankara.

Ünlü, Z. R. (2018). Sosyal medya bağımlılığı ve psikolojik dayanıklılık. (Yayımlanmamış yüksek lisans tezi). Üsküdar Üniversitesi, İstanbul.

Varıcier, Ş. E. (2019). Yetişkin psikolojik sağlamlı̆̆ üzerine bir inceleme: Algllanan ebeveyn tutumu, kontrol odağl, algllanan sosyal destek ve stresle başa çıkma stilleri. (Yayımlanmamış yüksek lisans tezi). İbn-i Haldun Üniversitesi, İstanbul.

Wagnild, G. M., \& Young, H. M. (1993). Development and psychometric evaluation of the Resilience Scale. Journal of Nursing Measurement, 1, 156-178. 
Yazıcı, E. (2019). Aile değerleri ile aile yılmazlı̆̆ı arasındaki ilişkinin incelenmesi. (Yayımlanmamış yüksek lisans tezi). İstanbul Üniversitesi, İstanbul.

Yılmaz, M. (2019). Ö̆gretmenlerin psikolojik dayanıklılıkları ile iş yaşam kaliteleri arasındaki ilişkinin incelenmesi. (Yayımlanmamış yüksek lisans tezi). Erzincan Binali Yıldırım Üniversitesi, Erzincan.

Zakeri, H. Jowkar, B., \& Razmjoee, M. (2010). Parenting styles and resilience. Procedia Social and Behavioral Science, 5, 1067-1070. doi: 10.1016/j.sbspro.2010.07.236 